\title{
Effects of Dibutyryl cyclic AMP on Sinus Rate and Atrial Contractile Force in the Isolated Atrium of the Dog
}

\author{
Shigetoshi Chiba \\ Department of Pharmacology, Tohoku University School of \\ Medicine, Sendai
}

\begin{abstract}
Chira, S. Effects of Dibutyryl Cyclic AMP on Sinus Rate and Atrial Contractile Force in the Isolated Atrium of the Dog. Tohoku J. exp. Med., 1975, 115 (1), 81-84 — In blood-perfused isolated canine atrium preparations, single injections of dibutyryl cyclic AMP at a dose range of 1 to $30 \mathrm{mg}$ were made into the cannulated sinus node artery. At doses above $3 \mathrm{mg}$, dibutyryl cyclic AMP induced a biphasic chronotropic and inotropic response; there was a slight and rapid negative chronotropic and inotropic response, followed by a long-lasting positive chronotropic and inotropic response. The induction of the positive effects was slow, and it took 4 to $8 \mathrm{~min}$ to reach a maximum response. These effects continued 20 to $60 \mathrm{~min}$. The ratios of the positive inotropic effect/ positive chronotropic effect were very similar to those induced by norepinephrine. In this study, it was confirmed that a large dose of dibutyryl cyclic AMP induced a positive chronotropic and inotropic effect on the canine atrium, and the possibility was discussed that cyclic AMP may be involved in the effects of betaadrenergic amines on the pacemaker and contractile process of the heart.

SA node; atrial muscle; isometric tension development; dibutyryl cyclic AMP; inotropism/chronotropism
\end{abstract}

In a previous paper, Chiba et al. (1972b) reported that dibutyryl cyclic AMP never induced any chronotropic response at a dose level of $100 \mu \mathrm{g}$ to $1 \mathrm{mg}$, using direct perfusion of the sinus node artery of the in situ dog heart (Hashimoto et al. 1967). However, Krause et al. (1970) reported that dibutyryl cyclic AMP produced a positive chronotropic response in cultures of spontaneously beating rat heart cells. Kukovetz and Pöch (1970), Skelton et al. (1970) and Ahren et al. (1971) have demonstrated apparent augumentation of contractility by dibutyryl cyclic AMP, although high concentrations of dibutyryl cyclic AMP are required to produce the apparent increase in contractility in those experiments.

In the present study, it was attempted to examine effects of a large dose level of dibutyryl cyclic AMP from 1 to $30 \mathrm{mg}$ on SA nodal pacemaker activity and atrial contractile force, using the blood-perfused isolated atrium preparation of the dog heart which originally developed by Chiba et al. (1972a).

Received for publication, November 27, 1974. 


\section{Methods}

Five mongrel dogs of either sex, weighing from 8 to $10 \mathrm{~kg}$, were anesthetized with sodium pentobarbital, $30 \mathrm{mg} / \mathrm{kg}$ i.v. The right atrium was excised and plunged into a Tyrode's solution at about $4^{\circ} \mathrm{C}$. The atrium was perfused under a constant pressure of $100 \mathrm{mmHg}$ through the cannulated sinus node artery with blood introduced from a heparinized support dog. The right atrium was suspended in a bath filled with blood at $37^{\circ} \mathrm{C}$. Isometric tension development was measured with a force displacement transducer (Grass FTO3B). The rate of isometric tension development, $d T / d t$, was obtained by electronic differentiation with an RC circuit. Atrial rate was measured with a tachometer which triggered by waves of atrial electrograms. DL-Norepinephrine hydrochloride (Sankyo) or $\mathrm{N}^{6}-2^{\prime}$-O-dibutyryl cyclic adenosine $3^{\prime}, 5^{\prime}$-monophosphate (supplied by Daiichi Seiyaku Co., Ltd.) was injected into the cannulated sinus node artery by means of a microinjector (Terumo Co.). The volume of injection of drugs was 0.01 to $0.03 \mathrm{ml}$ in a period of 4 sec.

\section{Results and Discussion}

Dibutyryl cyclic AMP was administered into the cannulated sinus node artery at a dose range from 1 to $30 \mathrm{mg}$. At a dose of $1 \mathrm{mg}$, dibutyryl cyclic AMP never induced any chronotropic or inotropic response. The threshold dose for inducing positive chronotropic and inotropic effects was approximately $3 \mathrm{mg}$. The induction of the effects was slow and it took 4 to $8 \mathrm{~min}$ to reach a maximum response. These effects usually continued for 20 to $60 \mathrm{~min}$. These long-lasting positive chronotropic and inotropic responses were preceded by rapid and slightly negative ones with durations within $1 \mathrm{~min}$. Fig. 1 shows typical responses to norepinephrine and dibutyryl cyclic AMP. Summarized data are shown in Table 1.

In a previous paper, Chiba et al. (1972b) failed to confirm that dibutyryl cyclic AMP produces a positive chronotropic response on the SA node preparation in the in situ dog heart, because of the use of a relatively small dose of dibutyryl cyclic AMP from $100 \mu \mathrm{g}$ to $1 \mathrm{mg}$. In the present experiments, a high dose level above $3 \mathrm{mg}$ of dibutyryl cyclic AMP significantly induced positive chronotropic

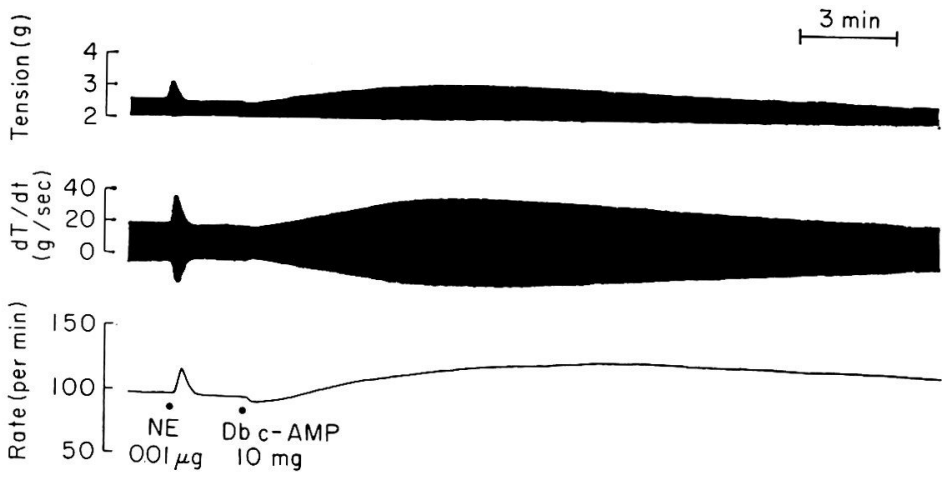

Fig. 1. Effects of norepinephrine (NE) and dibutyryl cyclic AMP (Db c-AMP) on the blood-perfused, isolated atrium of the dog heart. 
TABLE 1. Chronotropic and inotropic effects of dibutyryl cyclic AMP and norepinephrine on the blood-perfused, isolated atrium of the dog heart

\begin{tabular}{|c|c|c|c|c|c|}
\hline \multirow{2}{*}{ Dose } & \multicolumn{2}{|c|}{ Chronotropic effect } & \multicolumn{2}{|c|}{ Inotropic effect } & \multirow{2}{*}{$\begin{array}{l}\text { Ratio } \\
\text { PIE/PCE }\end{array}$} \\
\hline & $\begin{array}{c}\text { Decrease } \\
\text { in HR }(\%)\end{array}$ & $\begin{array}{c}\text { Increase } \\
\text { in } \mathrm{HR}(\%)\end{array}$ & $\begin{array}{l}\text { Deerease } \\
\text { in CF }(\%)\end{array}$ & $\begin{array}{l}\text { Increase } \\
\text { in } \mathrm{CF}(\%)\end{array}$ & \\
\hline \multicolumn{6}{|c|}{$\begin{array}{l}\mathrm{Db} \text { c-AMP } \\
(\mathrm{mg})\end{array}$} \\
\hline $\begin{array}{r}1 \\
3 \\
10 \\
30\end{array}$ & $\begin{array}{c}0 \\
0.8 \pm 0.8 \\
2.6 \pm 1.6 \\
7.0 \pm 1.0\end{array}$ & $\begin{array}{r}1.0 \pm 1.0 \\
3.6 \pm 1.5 \\
13.2 \pm 3.6 \\
21.0 \pm 5.7\end{array}$ & $\begin{array}{r}5.0 \pm 5.0 \\
15.0 \pm 9.8 \\
21.0 \pm 11.7 \\
20.6 \pm 10.4\end{array}$ & $\begin{array}{r}3.0 \pm 3.0 \\
14.2 \pm 7.5 \\
50.0 \pm 20.3 \\
85.0 \pm 34.3\end{array}$ & $\begin{array}{l}4.0 \\
3.8 \\
4.0\end{array}$ \\
\hline \multicolumn{6}{|c|}{$\begin{array}{l}\text { Norepinephrine } \\
\quad(\mu \mathrm{g})\end{array}$} \\
\hline $\begin{array}{l}0.01 \\
0.03 \\
0.1\end{array}$ & $\begin{array}{l}0 \\
0 \\
0\end{array}$ & $\begin{array}{r}8.0 \pm 1.2 \\
20.2 \pm 6.1 \\
52.7 \pm 10.9\end{array}$ & $\begin{array}{l}0 \\
0 \\
0\end{array}$ & $\begin{array}{r}35.7 \pm 8.3 \\
62.0 \pm 9.0 \\
173.1 \pm 42.0\end{array}$ & $\begin{array}{l}4.4 \\
3.1 \\
3.3\end{array}$ \\
\hline
\end{tabular}

Values represent the percentage increases from the initial sinus rate, 96.2 \pm 7.1 beats $/$ min (mean \pm s.E.), and isometric developed tension in 5 atrium preparations. CF, contractile force; Db c-AMP, dibutyryl cyclic AMP; HR, heart rate; PCE, positive chronotropic effect; PIE, positive inotropic effect.

and inotropic effects. The blood-perfused isolated atrium preparation was beneficial for observing the direct effect of dibutyryl cyclic AMP on SA nodal pacemaker activity and atrial contractile force, because it was not modified by extracardiac factors. Therefore, extremely large doses of dibutyryl cyclic AMP could administered directly to the atrium via the cannulated sinus node artery. As the perfusion flow rate of the sinus node artery was 1 to $5 \mathrm{ml} / \mathrm{min}$ in all 5 preparations, the injected dibutyryl cyclic AMP was the very high concentrations. In in situ preparations, a large dose of dibutyryl cyclic AMP induced systemic effect and the possibility that the observed changes have been reflexly induced cannot be ruled out.

As shown in Table 1, the ratio of the increase in atrial contractile force and the increase in sinus rate resulted by the administration of dibutyryl cyclic AMP was very similar to that obtained with norepinephrine. The positive inotropic effects of catecholamines have been postulated to result from an increase in the intracellular level of cyclic AMP produced by activation of adenyl cyclase (Murad et al. 1962; Robison et al. 1965). If the mechanism mentioned above is true, the present results may be reasonable. However, still it is not completely clear that an increase in the intracellular cyclic AMP causes a positive chronotropic and inotropic effect. Because, for producing a positive chronotropic and inotropic effect, extremely large doses of dibutyryl cyclic AMP were needed. Meinertz et al. (1972) reported that a positive inotropic effect could be observed in rat atria but not in guinea-pig atria by the use of large concentrations of dibutyryl cyclic AMP. Furthermore, Benfey (1971) described lack of relationship between myocardial cyclic AMP concentrations and inotropic effects of sympathomimetic amines, and 
suggested that cyclic AMP does not play an essential role in the effect of sympathomimetic amines on contractility.

\section{Acknowledgments}

I am grateful to Mr. Shoji Hayashi for his technical assistance.

\section{References}

1) Ahren, K., Hjalmarson, A. \& Isaksson, O. (1971) Inotropic and metabolic effects of dibutyryl cyclic adenosine $3^{\prime}, 5^{\prime}$-monophosphate in the perfused rat heart. Acta physiol. scand., 82, 79-90.

2) Benfey, B.G. (1971) Lack of relationship between myocardial cyclic AMP concentrations and inotropic effects of sympathomimetic amines. Brit. J. Pharmacol,, 43, $757-763$.

3) Chiba, S., Kubota, K. \& Hashimoto, K. (1972a) Double peaked positive chronotropic response of the isolated, blood-perfused S-A node to caffeine. Tohoku J. exp. Med., 107, 101-102.

4) Chiba, S., Kubota, K. \& Hashimoto, K. (1972b) Absence of chronotropic effects of dibutyryl cyclic adenosine 3',5'-monophosphate on the dog S-A node. Tohoku J. exp. Med., 107, 103-104.

5) Hashimoto, K., Tanaka, S., Hirata, M. \& Chiba, S. (1967) Responses of the sinoatrial node to change in pressure in the sinus node artery. Circulat. Res., 21, 297-304.

6) Krause, E.-G., Halle, W., Kallabis, E. \& Wollenberger, A. (1970) Positive chronotropic response of cultured isolated rat heart cells of ' $\mathrm{N}, 2^{\prime}$-O-dibutyryl-3', $5^{\prime}$-adenosine monophosphate. J. mol. cell. Cardiol., 1, 1-10.

7) Kukovetz, W.R. \& Pöch, G. (1970) Cardiostimulatory effects of cyclic 3,' 5'-adenosine monophosphate and its acylated derivatives. Naunyn-Schmiedebergs Arch. Pharmakol., 266, 236-254.

8) Meinertz, T., Nawrath, H. \& Scholz, H. (1972) U̇ber die positive inotrope Wirkung von Dibutyryl-3', 5'-AMP an isolierten Rattenvorhöfen. Pfiügers Arch ges. Physiol,, $333,197-212$.

9) Murad, F., Chi, Y.M., Rall, T.W. \& Sutherland, E.W. (1962) Adenyl cyclase: III. Effect of catecholamines and choline esters on the formation of adenosine $3^{\prime}, 5^{\prime}$. phosphate by preparations from cardiac muscle and liver. J. biol. Chem., 237, 12341238.

10) Robison, G.A., Butcher, R.W., Øye, I., Morgan, H.E. \& Sutherland, E.W. (1965) Effect of epinephrine on adenosine 3', 5'-phosphate levels in the isolated perfused rat heart. Mol. Pharmacol., 1, 168-177.

11) Skelton, C.L., Levey, G.S. \& Epstein, S.E. (1970) Positive inotropic effects of dibutyryl cyclic adenosine 3', 5'-monophosphate. Circulat. Res., 26, 35-43. 